\title{
Wind Pressures Distribution on Porous Exterior Walls of Buildings Double Skin façade System
}

\author{
Jwo-Hua Chen / Associate professor \\ Department of Spatial Design, \\ Chienkuo University of Technology \\ Changhua City, Taiwan ROC \\ rhchen@ctu.edu.tw \\ Ming-Chin Ho / Professor \\ Department of Architectural Design, \\ China University of Technology \\ Taipei City, Taiwan ROC
}

\author{
Yun-Lian Chern / Chief Secretary \\ Architecture and Building Research Institute, \\ Ministry of Interior, \\ Taipei City, Taiwan ROC
}

\begin{abstract}
A series of aerodynamics experiments were conducted to identify the effects of lateral leakages to the wind pressures distribution on the porous wall of buildings. The wind pressures distribution on the porous exterior walls of buildings had been studied by aerodynamic experiments in wind tunnel. The results showed, the lateral leakage will affects the net pressures of walls and especially for the two side leakage. With the lateral leakage, the net pressures on porous exterior walls might be increase for the gap ratio over $10 \%$. But if the leakage location were on the top of wall, the increment of net pressure would not be evident. In general, the lateral leakage would reduce the wind loadings on exterior wall with enough gap ratio. These factors in order of effect will be "two side and top opening", "two side opening" and "top opening". For variant opening ratio of the porous exterior walls, net pressures on walls would be reduced in the larger opening ratio cases. In this study for the cases of opening ratio larger than $2.4 \%$, the wind pressures will be reduced evidently.
\end{abstract}

Keywords—wind loadings; double-skin facade; wind tunnel tests

\section{INTRODUCTION}

Base on the purpose of energy saving and improving the outward appearance, lots of double skin facades are adopted in the design of buildings. This system can also incorporate with the natural ventilation, thermal environment adjusting. However, in the design stage the suitable wind loadings on exterior walls should be decided firstly. In the design stage, such as the gap of double skin walls, opening on the exterior walls and lateral leakage will be important factors. In this study, the effects of the above factors will be checked with a series of aerodynamics models experiments in wind tunnel. ${ }^{1}$

\section{BACKGROUND}

For the reason of ventilation, many exterior walls of double skin façade system will be set with openings and

\footnotetext{
${ }^{11}$ Thanks to the Architecture and Building Research Institute, Ministry of Interior of Taiwan ROC for the financial and facility support.
}

caused the porous type exterior walls [1]. During the typhoon season of Taiwan, these exterior walls may be damaged by strong wind or wind debris. Surrounding turbulence flow of building will be conducted into the interior space, and the internal pressures are varied with the turbulent flow in the same time. With the combined external and internal pressures of walls may make more damages to the claddings of buildings and it should be paid more attention on them.

\section{EXPERIMENTS SETUP AND DATA ANALYSIS}

\section{A. Experiments Setup}

A series of aerodynamics experiments were conducted at an open suction type wind tunnel in the Wind Eengineering Research Center of the Tamkang university of Taiwan, in which the constant-area test section is $1.8 \mathrm{~m}$ (height) $\times 1.2 \mathrm{~m}$ (width) $\times 12 \mathrm{~m}$ (length) and can provide wind speed from 1 to $25 \mathrm{~m} / \mathrm{sec}$. The grid generated intensity of turbulence is $13 \%$.

The dimension of buildings model is $30 \mathrm{~cm}$ (height), $30 \mathrm{~cm}$ (width), $20 \mathrm{~cm}$ (depth) and made by $3 \mathrm{~mm}$ thickness acrylic board. These typical double skin facades building models are showed as Fig. 1. With the changeable exterior wall, there are three kind of openings ratio on the exterior walls, they are $0.6 \%, 1 \%$ and $2.4 \%$. The two lateral sides and top of exterior walls also be set with openings which can be controlled to be open or close. In the mean while the exterior walls with openings conditions can be treat as "porous exterior walls". Also the gap between exterior walls and building body can be adjusted. In this study the gap ratio $(\mathrm{G})$ used are $3.3 \%, 6.7 \%, 10 \%$ and $16.7 \%$

As showed in Fig. 1, two side of exterior walls are set with uniform distributed pressure taps. The 50 pressures tap were divided into two equal groups, the external pressures and internal pressures measurement respectively. An electronic scani-valves system is used to collect the simultaneous pressures of model pressure taps, and the signals are sent into the A/D convertor, saved in PC for following analysis procedures. The sampling rate is set in 
$250 \mathrm{~Hz}$ and 31,000 data points in each record. The model is installed on a turn table in wind tunnel and mount above the test section floor. Therefore, we can rotate the turn table for variant angle to represent the wind azimuth angle. In this study all experiments are conducted with the normal wind action, so the wind azimuth angle is aligned to zero degree.

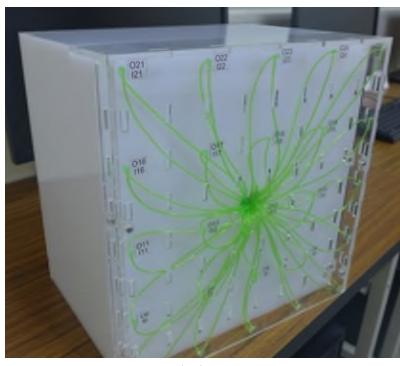

(a)

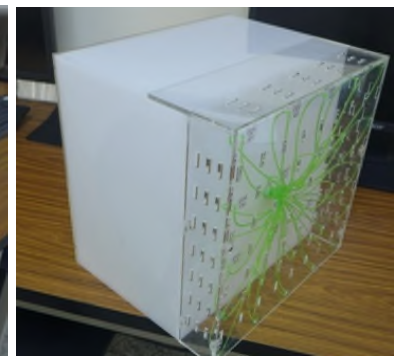

(b)
Fig. 1. Typical double skin facades building model with variant openings and gap. (a) $10 \mathrm{~mm}$ gap (b) $50 \mathrm{~mm}$ gap.

\section{B. Data Analysis}

In analysis procedures, the definitions of some calculated pressure coefficients are stated as below. The coefficients of mean pressure is defined as,

$$
C_{P}=\bar{P} /\left(\frac{1}{2} \rho U^{2}\right)
$$

where the $\rho$ is air density $\left(\mathrm{kg} / \mathrm{m}^{3}\right), \mathrm{U}$ is reference velocity $(\mathrm{m} / \mathrm{sec}), \bar{p}$ is mean pressure $\left(\mathrm{kgf} / \mathrm{m}^{2}\right)$ which has been subtracted the reference pressure. Mean velocity of test section is took as the reference velocity and the static pressure of flow field is took as the reference pressure.

The coefficients of mean pressure is defined as,

$$
C_{P}^{\prime}=\frac{\sqrt{\overline{P^{\prime 2}}}}{\frac{1}{2} \rho U^{2}}
$$

where $\sqrt{\overline{p^{\prime 2}}}$ is the fluctuating pressures

Each pressure tap location on exterior walls has been set two pressure tap, external and internal. The so called net pressures, $\mathrm{C}_{\mathrm{pn}}$, are considered in this study and the definition is showed as following,

$$
C_{p n}=C_{p e}-C_{p i}
$$

where the $C_{p e}$ is the external wind pressure coefficients, and the $\mathrm{C}_{\mathrm{pi}}$ is internal wind pressures of exterior porous walls.

The ratio of gap $(\mathrm{G})$ is calculated by

$$
G=S / \sqrt{B H}
$$

where the $S$ is spacing of the two walls of double skin façade, $B$ is building width and $H$ is building height.

\section{RESUlTS AND DisCUSSIONS}

According to the results of the experiments and analysis, some characteristics about the wind pressures distribution on the exterior porous walls are discussed as following.

\section{A. Effects of Gap Ratio}

Gap between the exterior wall and building may cause the internal pressure, can also be called as back pressure, of exterior wall changed due to the entrainment of on-coming turbulent flow. As the Fig. 2 showed, pressures distribution on exterior walls will change evidently with the gap ratio. In the meanwhile, the increased gap ratio will cause the net pressure increased also. Especially, for the gap ratio higher than $10 \%$, the positive pressures distributed area will be extended. In this case, the on-coming turbulent flow can entrain into the back of exterior wall and go out by the path of two side openings. But the center area of back face of exterior walls, it seems the internal pressure would be kept in a lower situation. Also the center area is close to stagnation point phenomenon, the positive external pressures will be higher than the other area. Therefore, the positive external pressure combined with internal pressure will cause the higher net pressure coefficients in this area.

(a)

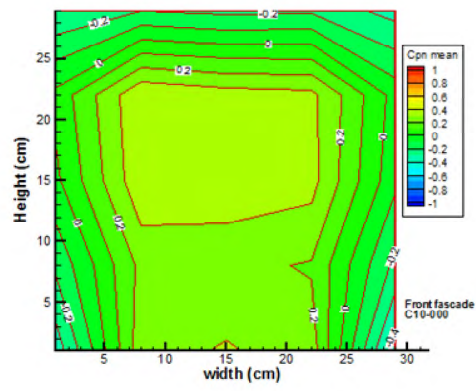

(b)
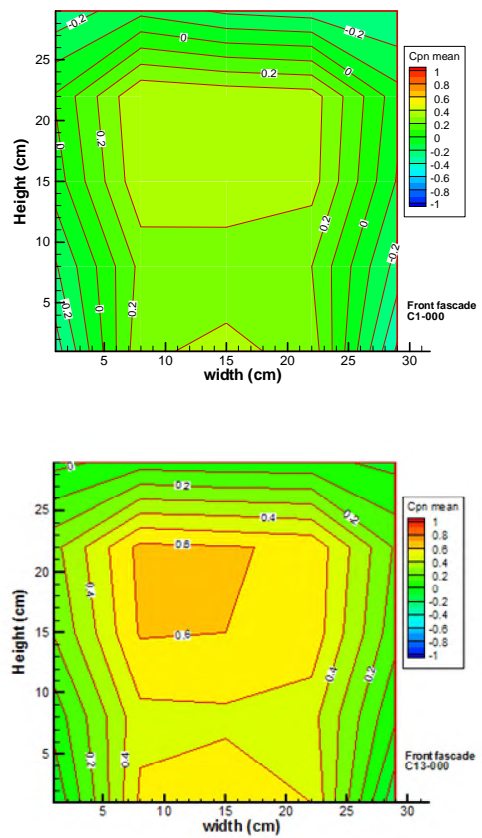

(c) 
(d)

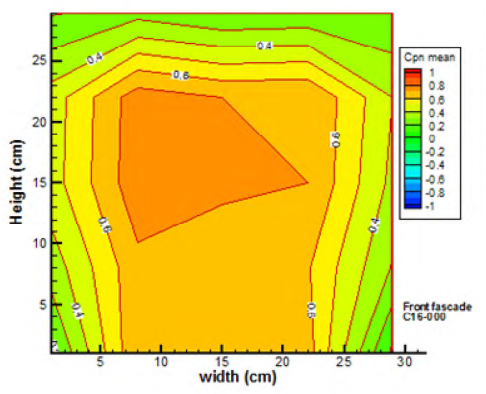

Fig. 2. The mean net pressures coefficients distribution of two side leakage exterior walls with opening ratio $2.4 \%$ and gap ratio is (a) $3.3 \%$ (b) $6.7 \%$ (c) $10 \%$ (d) $16.7 \%$

(a)

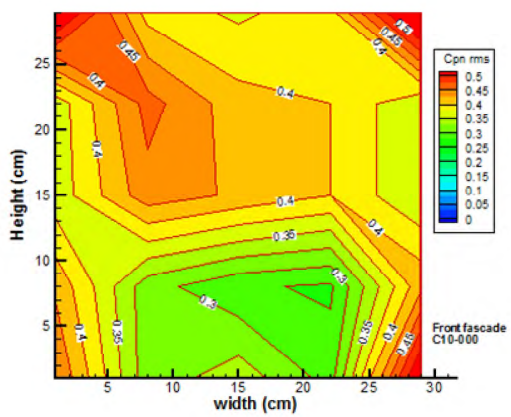

(b)

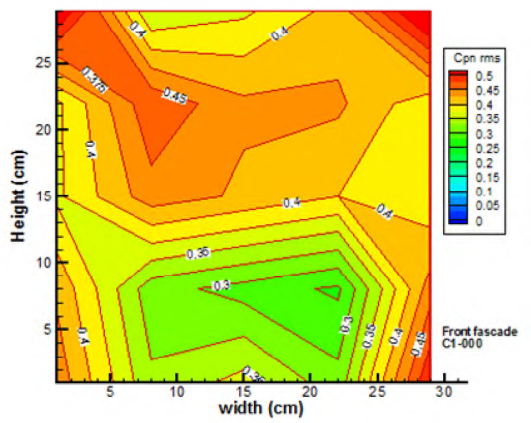

(c)

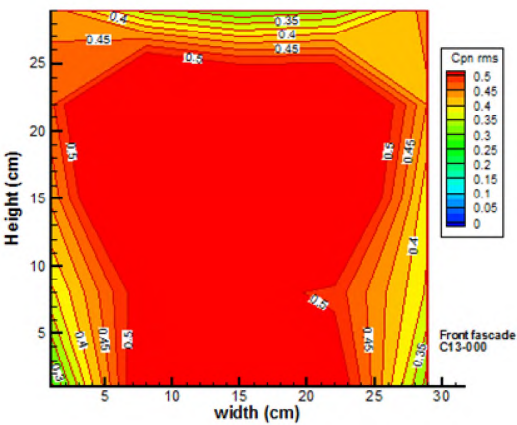

(d)

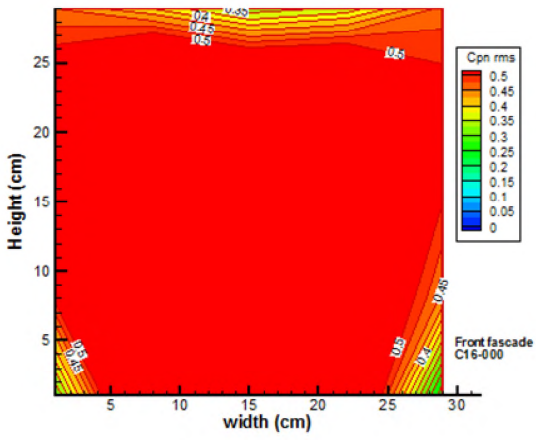

Fig. 3. The fluctuating net pressures coefficients distribution of two side leakage exterior walls with opening ratio $2.4 \%$ and gap ratio is (a)3.3\% (b) $6.7 \%$ (c) $10 \%$ (d) $16.7 \%$

Also the fluctuating pressure distributions are checked and showed in Fig. 3. As the gap ratio increased, the fluctuating pressure will be rose up. For the cases of gap ratio more than $10 \%$, the high fluctuating pressure distribution will cover almost whole front walls. This depicted the large gap will introduce more turbulent flow into the back region of exterior walls and enhanced the fluctuating pressure. So the large gap may increase the risk of cladding destroyed or damaged by the peak gust wind.

(a)
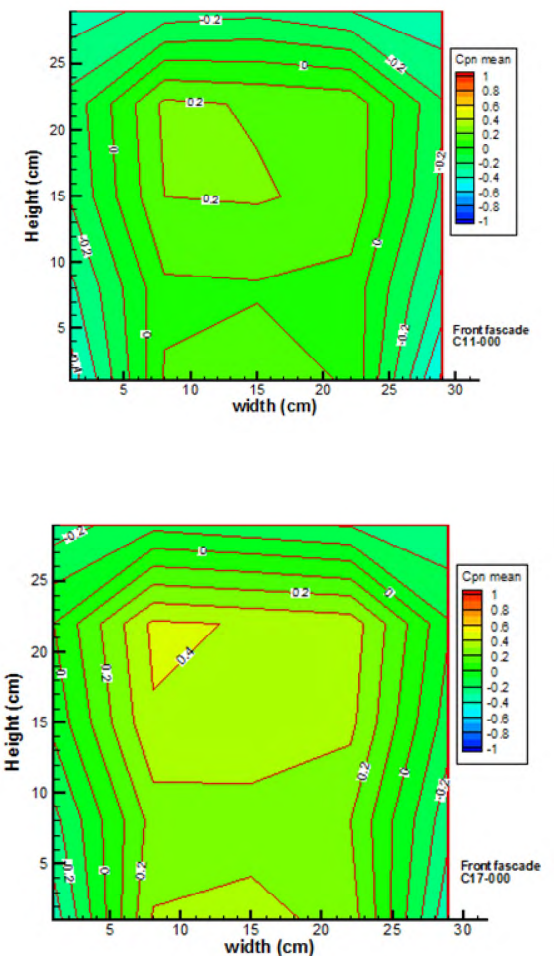

(b)

Fig. 4. The mean net pressures coefficients distribution of top leakage exterior walls with opening ratio $2.4 \%$ and gap ratio is (a) $3.3 \%$ (b) $16.7 \%$

\section{B. Effects of Lateral Leakage Location}

For comparison, the lateral leakages are set at top of wall, and the mean net pressure coefficients distribution is showed 
as Fig. 4. Evidently, the recovery of mean net pressures coefficients is less than the two side opening cases. For the turbulent flow normal to the wall, the wind pressures will be affected by the back pressures of exterior walls deeply. So when the leakage location at the top region, high speed overhead flow on the top of building, only the flow near this region may entrain into the back region of wall. The most part of back region do not affected by turbulent, even the gap ratio is high. The total net pressure on the porous exterior wall is close to neutral, so we may say the external and internal pressure will be balance when compared to the other cases. Fig. 5 showed the net fluctuating pressure of exterior wall, it is evident that the fluctuating pressure is lower than the above case. That means less turbulent got into the back region when the opening located at top region of exterior wall. As the gap ratio increased, the corner region changed into neutral. About the fluctuating net pressures, is showed in the Fig. 5. The high fluctuating region is on the corner region, but the upper part surface of walls will slightly increase with the gap ratio .Especially for the cases of gap ratio over $10 \%$ will be more clearly.

(a)
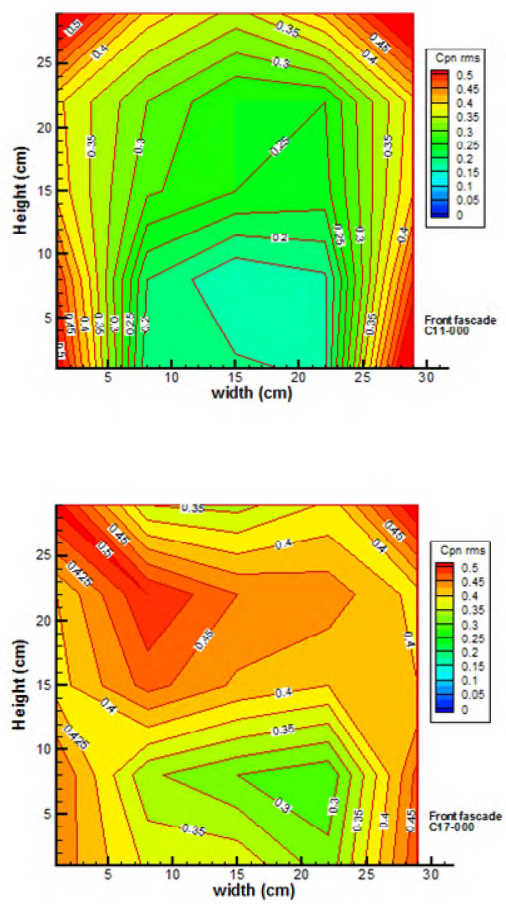

(b)

Fig. 5. The fluctuating net pressures coefficients distribution of top leakage exterior walls with opening ratio $2.4 \%$ and gap ratio is (a) $3.3 \%$ (b) $16.7 \%$

The mean net pressures coefficients distribution of top and side leakages exterior walls with opening ratio $2.4 \%$ and variant gap ratio is showed in Fig. 6. The pressure recovery on the exterior walls is very evident. Base on the entrainment of two side leakage and combined with the leakage effects of top region, so the pressure on the back region is very strong. The similar situation can be found at the fluctuating net pressure distribution, shoed at Fig. 7. (a)
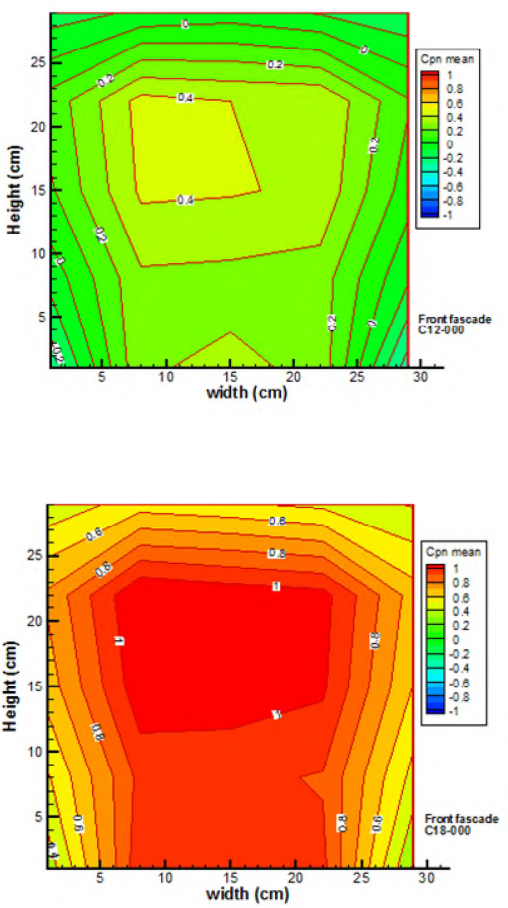

Fig. 6. The mean net pressures coefficients distribution of top and side leakages exterior walls with opening ratio $2.4 \%$ and gap ratio is (a) $3.3 \%$ (b) $16.7 \%$

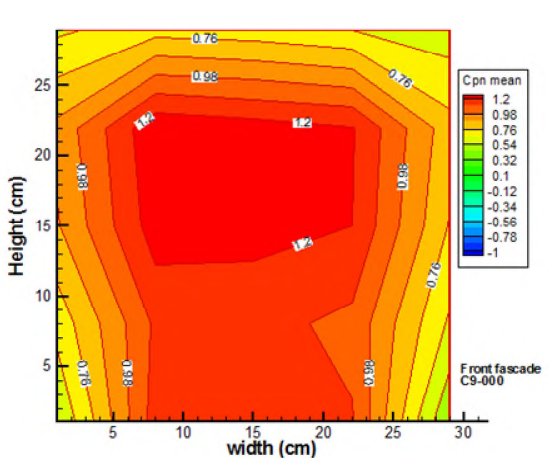

(a)

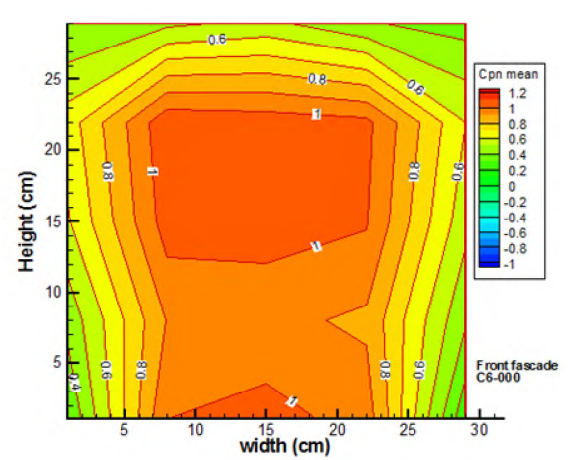

(b) 


\section{(c)}

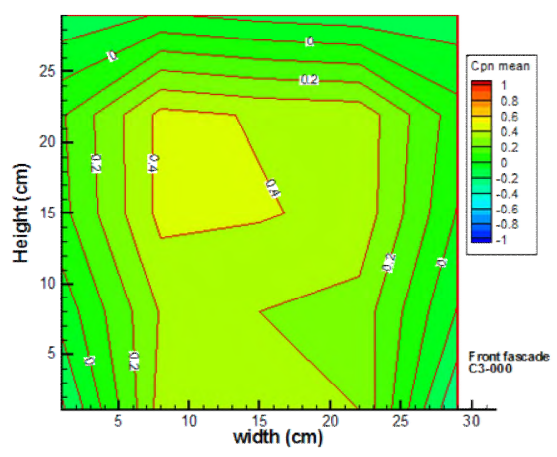

Fig. 7. The mean net pressures coefficients distribution of top leakages exterior walls with gap ratio $6.7 \%$ and opening ratio is (a) $0.6 \%$ (b) $1 \%$ (c) $2.4 \%$

\section{Effects of Opening Ratio}

In the study of opening ratio effects to the wind pressures on the exterior walls, the top leakage and gap ratio $6.7 \%$ model is considered. The mean and fluctuating net pressure distribution are showed in Fig. 7 and Fig. 8, respectively. In Fig. 7 the mean pressure is decreased for the higher opening ratio and similar trend for the fluctuating net pressures in the Fig. 8. So the pressures distribution on the both façade of porous exterior walls will be balanced due to the large opening ratio. For the exterior walls, the higher opening ratio will ease the wind loadings on exterior walls.

(a)

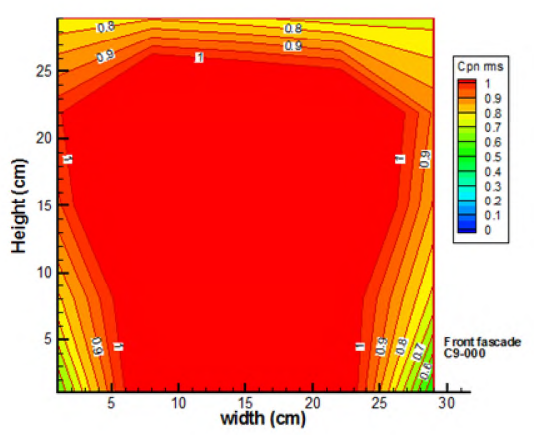

(b)

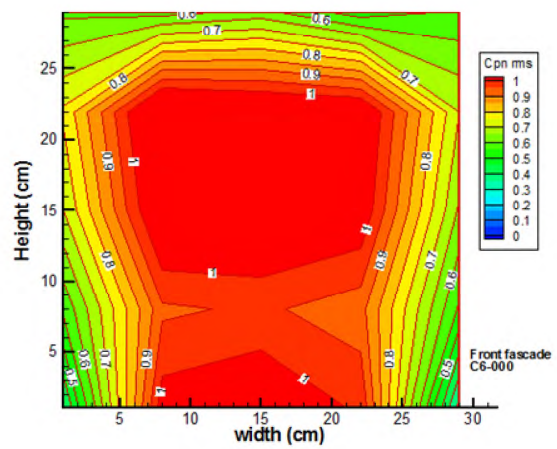

(c)

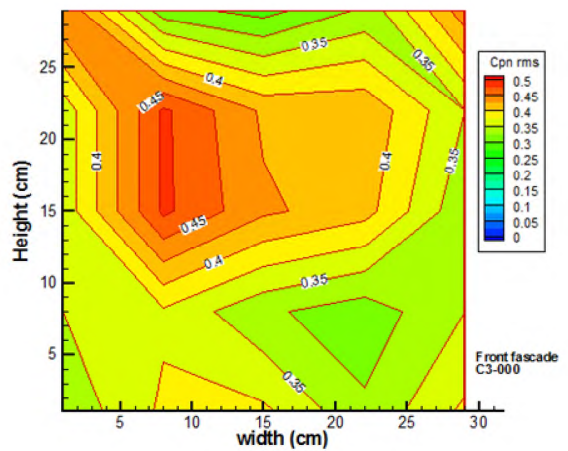

Fig. 8. The fluctuating net pressures coefficients distribution of top leakages exterior walls with gap ratio $6.7 \%$ and opening ratio is (a) $0.6 \%$ (b) $1 \%$ (c) $2.4 \%$

\section{CONCLUDING REMARKS}

With the typical double skin building models, the wind pressures distribution on the porous exterior walls of buildings had been studied by aerodynamic experiments in wind tunnel and a uniform turbulent flow field was adopted. The results showed, the lateral leakage will affects the net pressures of walls and especially for the two side leakage. With the lateral leakage, the net pressures on porous exterior walls might be increase for the gap ratio over $10 \%$. But if the leakage location were on the top of wall, the increment of net pressure would not be evident. In general, the lateral leakage would reduce the wind loadings on exterior wall with enough gap ratio. These factors in order of effect will be "two side and top opening", "two side opening" and "top opening".

For variant opening ratio of the porous exterior walls, net pressures on walls would be reduced in the larger opening ratio cases. In this study for the cases of opening ratio larger than $2.4 \%$ would reduce the wind pressures dramatically. So for the buildings equipped with double skin façade or the flat pasted advertisement boards on buildings, the enough opening is very important factor to prevent the large wind loadings on them.

\section{REFERENCES}

[1] H. Poirazis, Double Skin Façades for Office Buildings, Department of Construction and Architecture, Division of Energy and Building Design. Lund University, Lund Institute of Technology, Lund, 2004.

[2] M.C. Ho and J.H. Chen, "The characteristics of wind loadings on the low-rise buildings with gable roofs", J. Archit. vol. 62, pp. 99-116, 2007. 